CARPATHIAN JOURNAL OF FOOD SCIENCE AND TECHNOLOGY

journal homepage: http://chimie-biologie.ubm.ro/carpathian_journal/index.html

\title{
EFFECT OF MICROENCAPSULATION AND COATING ON THE SURVIVABILITY OF LACTOBACILLI PROBIOTICS IN YOGURT AND GASTROINTESTINAL CONDITIONS
}

\author{
Hadi Pourjafar ${ }^{1,2 \bowtie}$, Negin Noori ${ }^{3}$, Hasan Gandomi ${ }^{3}$, Afshin Akhondzadeh Basti ${ }^{3}$, \\ Fereshteh Ansari ${ }^{4,5,6}$ \\ ${ }^{I}$ Alborz University of Medical Sciences, Dietary Supplements and Probiotic Research Center, Karaj, \\ Iran \\ ${ }^{2}$ Department of Food Sciences and Nutrition, Maragheh University of Medical Sciences, Maragheh, Iran \\ ${ }^{3}$ Department of Food Hygiene, Faculty of Veterinary Medicine, University of Tehran, Iran \\ ${ }^{4}$ Razi Vaccine and Serum Research Institute, Agricultural Research, Education and Extension Organization \\ (AREEO), Tehran. Iran \\ ${ }^{5}$ Research Center for Evidence-Based Medicine, Health Management and Safety Promotion \\ Research Institute,, Tabriz University of Medical Sciences, Tabriz, Iran \\ ${ }^{6}$ Iranian EBM Centre: A Joanna Briggs Institute Affiliated Group, Tabriz, Iran \\ ๑pourjafarhadi59@ut.ac.ir \\ https://doi.org/10.34302/crpjfst/2021.13.1.10 \\ Article history: \\ Received: \\ 23 June 2019 \\ Accepted: \\ 25 December 2020 \\ Keywords: \\ Microencapsulation; \\ Double coating; \\ Probiotics; \\ Yogurt; \\ GI condition; \\ Viability

\section{ABSTRACT} \\ Microencapsulation of probiotics is an efficient way that can improve the \\ viability rate of them in dairy products like yogurt as well as in lumen tract \\ conditions. The viability of free and microencapsulated forms of \\ Lactobacillus rhamnosus and Lactobacillus acidophilus were evaluated in \\ yogurt and under simulated gastrointestinal conditions. Microencapsulation \\ and double coating process carried out by alginate-chitosan and Eudragit \\ S100 nanoparticles and by the extrusion method. Bacterial count (cfu g-1) \\ of L. acidophilus reduced from $7.0 \times 10^{8}$ to $4.2 \times 10^{6}$ in day 0 and in day 42 in \\ yogurt containing free bacteria, while the bacterial count of \\ microencapsulated bacterium showed a reduction from $3.3 \times 10^{7}$ to $2.5 \times 10^{7}$. \\ Microencapsulation of L. rhamnosus could also increase the viability of this \\ bacterium; $3.2 \times 10^{9}$ to $5.8 \times 10^{6}$ bacterial count by reduction of free-form \\ storage, and $7.6 \times 10^{9}$ to $3.4 \times 10^{8}$ bacterial count by reduction of \\ microencapsulated form in 42 days. On day 14 (first day of bacterial count \\ in gastrointestinal condition) L. acidophilus count was $1.3 \times 10^{3}$ and $5.0 \times 10^{7}$ \\ which reached $2.0 \times 10^{0}$ and $2.8 \times 10^{4}$ on day 42 in free and microencapsulated \\ forms respectively. The bacterial count of L. rhamnosus decreased from \\ $1.2 \times 10^{3}$ to $5.0 \times 10^{0}$ in free form, and from $2.5 \times 10^{7}$ to $2.8 \times 10^{4}$ in \\ microencapsulated one. The results of this study suggest that this method of \\ microencapsulation can improve the viability of $L$. rhamnosus and $L$. \\ acidophilus in yogurt and in the simulated human gastrointestinal tract.
}

\section{Introduction}

Probiotics are identified as live microbial foodstuff supplements which benefit the host via improving its intestinal microbial equilibrium. These microorganisms can be formulated in several special kinds of manufactured goods including foodstuffs, medicines, and nutritional complements (Gibson, Probert, Van Loo, Rastall, \& Roberfroid, 2004). Identified healthiness advantages of probiotic strains comprise suppressing the development of unwanted microbes in the small intestine and 
colon, immunomodulating the immune system, reducing serum cholesterol heights, improving lactose consumption, and so on (Huang, Shen, Liang, \& Jan, 2016; Rijkers et al., 2010; Tabrizi et al., 2019; Ansari, Pourjafar, Tabrizi, \& Homayouni, 2020).

Foodstuffs including at least $107 \mathrm{cfu}$ g-1 probiotic microorganisms at the time of consumption are called "probiotic food products". Dairy products like yogurt, buttermilk, cheese, and ice-cream are common probiotic foods. Fermented dairy products with some specific properties like proper taste, aroma, and oral sense are appealing to all age groups, therefore they can be considered as appropriate carriers for probiotic microorganisms (Anal \& Singh, 2007; Granato, Branco, Cruz, Faria, \& Shah, 2010).

Lactic acid bacteria, especially Lactobacilli are the main probiotic microorganisms of the human gastrointestinal (GI) lumen. The proper adhesion of Lactobacilli to the enterocytes and their advanced health effects has led this genus of probiotic bacteria to be the most illustrated and applicable among other probiotic genera (Bernet, Brassart, Neeser, \& Servin, 1994; Kandasamy et al., 2016).

Generally, for applying every probiotic microorganism in dairy products some features need to be addressed, for instance, the viability of the microbes in the dairies, the chemical, physical and organoleptic characteristics of the final product, and the probiotic's healthiness and outcomes. The viability of these microbes during the processing and storage time has a significant role in the induction of their asserted healthiness effects. Exposure to acid and bile, oxidative stress, osmotic pressure, and cold stress may possibly diminish the number of probiotic bacteria under the effective threshold (Frederico et al., 2016; Ranadheera, Evans, Adams, \& Baines, 2012).

Microencapsulation of probiotics is an efficient method that can improve the survival rate of these microorganisms in dairy products like yogurt as well as in GI tract conditions. As a matter of fact, microencapsulation permits the probiotics to be separated from their surroundings via a protective covering (Rocha, 2016). Some investigations have reported the method of the microencapsulation by using calcium alginate and coating it with chitosan, which can provide protection for probiotic microorganisms. These materials have also been used widely for immobilization of probiotic microorganisms due to the reason of ease of use, its non-toxic characteristic, and its low cost (Ansari, Pourjafar, Jodat, Sahebi, \& Ataei, 2017; Chávarri et al., 2010; Crcarevska, Dodov, \& Goracinova, 2008; Kanmani et al., 2011).

Chitosan is a linear polysaccharide with a positive charge that is structured through deacetylation of chitin. Chitosan is water soluble in lower than $\mathrm{pH} 6$ and makes coagulation via ionotropic gelation. This polysaccharide is able to cross-link with anions or polyanions, such as Eudragit substance (Abouhussein, El-bary, Shalaby, \& El Nabarawi, 2016; Ahmed \& Aljaeid, 2016).

Eudragit $(\mathrm{Eu})$ is a trade name for Rohm $\mathrm{GmbH} \&$ Co. KG. Darmstadt in Germany, originally marketed during the 1950s. This product is prepared by the polymerization of acrylic and methacrylic acids or their esters, such as dimethylamino ethyl ester or butyl ester. $\mathrm{Eu}$ powder products are unique polymers with different grades of solubility. Eu polymers are non-toxic and food-grade polymers. Alternatives to Eu polymer are employed to coat solid medicines which used orally, for instance, granules, pills or capsules. Eu S100 is an anionic copolymer (one kind of the Eu polymers) derived from methacrylic acid and methyl methacrylate (1:2 proportion). This material is insoluble in water and acids, but soluble in aqueous solution at $\mathrm{pH} 7$ or higher. Therefore, this $\mathrm{pH}$-sensitive polymer doesn't release its contents in the stomach $(\mathrm{pH} \mathrm{1.5-2),} \mathrm{but} \mathrm{in} \mathrm{the}$ distal small intestine and in the colon $(\mathrm{pH} \mathrm{7)}$ as an aimed organ, and it seemed that this polymer can carry probiotic bacteria similar to it carrying solid medicines to colon in a safe way (Badhana, Garud, \& Garud, 2013; Hu, Liu, Chen, Li, \& Zhao, 2012; Thakral, Thakral, \& Majumdar, 2013). 
Double coating of calcium alginate beads by chitosan (first coat) and Eu S100 nanoparticles (second coat) that contains probiotic bacteria, is one of the newest kind of microencapsulation methods that we applied for achieving suitable strength in the bead's wall with a smooth surface (smother surface more strength in bead's wall). Nanoparticles in preference to $\mathrm{Eu}$ powder is founding of a thin nanosize layer in the coating of the beads. This particularly thin layer is potentially able to enhance the strength of beads with no increase in the size of them. Smaller beads perhaps may reduce the oral sense of beads in a food carrier as well as diminishing use of Eu powder (Younis, Shaheen, \& Abdallah, 2016).

Yogurt is one of the high-consumption product and favorite dairy can be used as a probiotic carrier. Several factors possibly will have an effect on the continued existence of probiotic microorganisms in yogurt. Final $\mathrm{pH}$ at the end of yogurt fermentation shows to be the main significant factor influencing the growth and survival of probiotic microorganisms (Akın, Akın, \& Kırmac1, 2007; Hekmat \& Reid, 2006; Mortazavian et al., 2007).

The goal of this study is to evaluate the effects of calcium alginate-chitosan and $\mathrm{Eu}$ S100 nanoparticles microencapsulation on the viability of probiotic bacteria (Lactobacillus acidophilus and Lactobacillus rhamnosus) under simulated GI conditions and during storage in yogurt. (Body text TNR 12, normal, indent first line $0.66 \mathrm{~cm}$, line spacing Single)

The content of yoghurt, which is produced with lactic acid fermentation using Streptococcus thermophilus and Lactobacillus delbrueckii subsp. bulgaricus and has a rich content in terms of carbohydrates, protein, fat, vitamins, calcium and phosphate, show similarities with milk, however, differences occur due to fermentation (Shahani et al., 1979; Caglar et al., 1999). The positive effects of yoghurt-like fermented dairy products on human health have been determined. Yoghurt, which is suitable for lactose intolerant individuals, is also easy to digest (Dewit, 2010; Pochart and Desjeux, 1988).

\section{Materials and methods}

\subsection{Preparation of probiotic bacteria}

Probiotic cultures of L. rhamnosus (PTCC 1469) and L. acidophilus (PTCC 4356) were achieved as of Iranian Research Organization for Science and Technology (IROST) and inoculated into MRS-broth (de Man-RogosaSharpe) and incubated at $37 \pm 2{ }^{\circ} \mathrm{C}$ for $24 \mathrm{~h}$ in aerobic conditions. The probiotic growth in late$\log$ phase was collected by means of centrifugation (Centrion Centrifuge, Model 2010, West Sussex, BNI8OHY, UK) at 5,000 rpm for $10 \mathrm{~min}$, and afterward it was washed two times in sterilized distilled water before employing in the microencapsulation procedure (Mirzaei, Pourjafar, \& Rad, 2011).

\subsection{Preparation of chitosan solution}

For the preparation of chitosan solution, 0.4 g low-molecular-weight chitosan (Sigma, USA) blended with $90 \mathrm{~mL}$ distilled water and acidified using $0.4 \mathrm{~mL}$ of glacial acetic acid (Merk, Darmstadt, Germany). Then, the $\mathrm{pH}$ was regulated in 5.6-5.8 using adjoining 1 mol L-1 $\mathrm{NaOH}$, and the solution was filtered through Whatman \#4 paper filter and the extent was adjusted to $100 \mathrm{~mL}$ before sterilizing into the autoclave $\left(121^{\circ} \mathrm{C}, 15 \mathrm{~min}\right)$. Finally, the chitosan solution was held at $5{ }^{\circ} \mathrm{C}$ overnight (Crcarevska et al., 2008; Kanmani et al., 2011; Lee, Cha, \& Park, 2004).

\subsection{Preparation of Eudragit $\mathbf{S 1 0 0}$ nanoparticles}

For preparing the $\mathrm{Eu} \mathrm{S100} \mathrm{nanoparticles}$ from, $\mathrm{Eu}$ S100 copolymer powder (EvonikPharma Polymers, Darmstadt, Germany), we used Supercritical Antisolvent Technique (SAS), this technique was employed and option of acetone was applied as a solvent for $\mathrm{Eu}$ powder (as a modified SAS process; we utilized homogenization power as a replacement for using high pressure). In this method, $4 \mathrm{mg}$ $\mathrm{mL}-1$ of Eu solution was applied in distilled water slowly as a supercritical fluid that had been held below homogenization pressure (Wisetise, DAIHAN Scientific Co., Ltd, Korea) at $26,000 \mathrm{rpm}$ at $35^{\circ} \mathrm{C}$ for $10 \mathrm{~min}$. Also, distilled 
water as a surfactant included $15 \mathrm{mg}$ L-1 Tween 80 (Merk, Hohenbrunn, Germany). Lastly, the acetone solvent was evaporated. The particle size of the Eu and PDI (polydispersibility/polydispersivity index) were assessed using Laser Particle Size Analyzer device (Brookhaven Instruments Corporation, USA) (Hari, Lu, Narayanan, Wang, \& Zheng, 2016; $\mathrm{Hu}$ et al., 2012; Pourjafar, Noori, Gandomi, Basti, \& Ansari, 2018; Yoo, Giri, \& Lee, 2011).

\subsection{Microencapsulation process}

\subsubsection{Primary microencapsulation process}

In this process, $4 \mathrm{~g} 100 \mathrm{~mL}-1$ sodium alginate (Sigma, USA) was blended with distilled water and then sterilized and kept in 5 ${ }^{\circ} \mathrm{C}$ overnight. Following day, $10 \mathrm{~mL}$ of probiotic suspension $(2 \times 1010 \mathrm{cfu} \mathrm{mL}-1)$ was added to the sodium alginate liquid. Subsequently, the mixture of the bacterial suspension and sodium alginate was injected into sterile $0.1 \mathrm{~mol} \mathrm{~L}-1$ $\mathrm{CaCl} 2$ (Merk, Darmstadt, Germany) fluid by means of sterile insulin syringes $(0.2 \mathrm{~mm})$ (extrusion technique was used for encapsulation process). After applying the drops into $\mathrm{CaCl} 2$ solution, the drops immediately turned into clot balls (the space between the $\mathrm{CaCl} 2$ solution and syringe needle was roughly $20 \mathrm{~cm}$, and we applied as much pressure as possible to the syringe to force the solution out extremely fast), and in 60 minutes, the entire beads were gathered and washed with distilled water (Abdolhosseinzadeh, Dehnad, Pourjafar, Homayouni, \& Ansari, 2018; Ghasemnezhad, Razavilar, Pourjafar, Khosravi-Darani, \& Ala, 2017). (See Fig. 1)

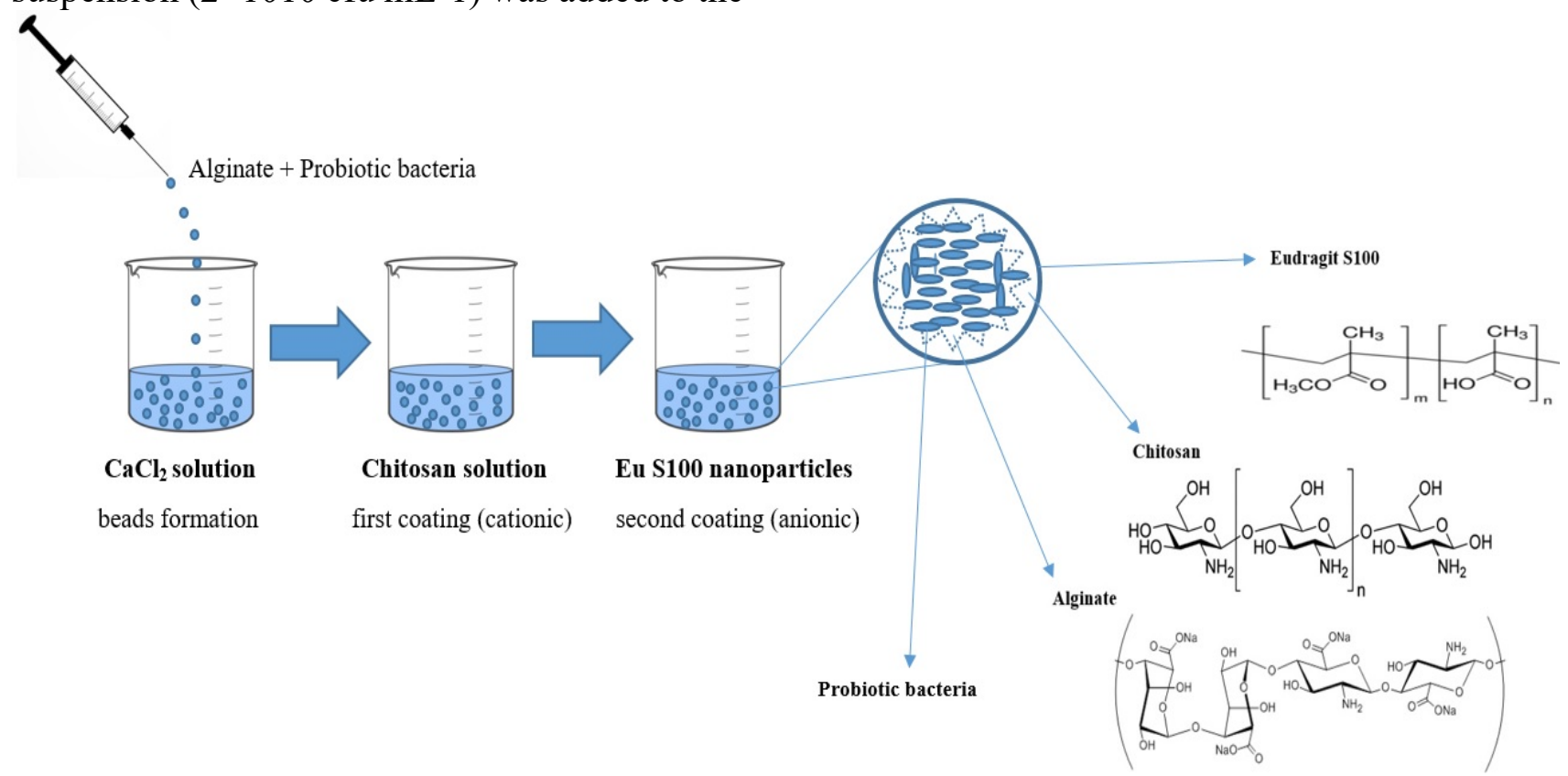

Figure 1. Microencapsulation process: Primary microencapsulation, the first coating of beads with chitosan solution, and the second coating of beads by Eudragit S100 nanoparticles. The final structure of formed beads has been illustrated.

\subsubsection{The first coating of beads with chitosan solution}

For the primary coating of the beads, they were submerged in $100 \mathrm{~mL}$ of chitosan solution lightly shaken at $100 \mathrm{rpm}$ for $40 \mathrm{~min}$ on a magnetic stirrer (IKA Labortechnik, Model 79219 staufen, KG, Germany). Then, the chitosan coated beads (single coated) were collected and rinsed with distilled water (Chávarri et al., 2010; Kanmani et al., 2011; Mirzaei et al., 2011). (See Fig. 1)

\subsubsection{The second coating of beads by Eudragit S100 nanoparticles}

For second coating of beads previously coated by chitosan (single coated beads), the 
beads were immersed in $100 \mathrm{~mL} \mathrm{Eu} \mathrm{S100}$ nanoparticles solution (4 mg $100 \mathrm{~mL}-1)$ and held for $4 \mathrm{~h}$ on the shaker (100 rpm) (Badhana et al., 2013; Hu et al., 2012; Yoo et al., 2011). Finally, the double-coated beads were washed thoroughly with distilled water and applied on the same day. (See Fig. 1)

\subsection{Probiotic yogurt preparation}

Yogurt was manufactured by heating reconstituted skimmed milk $(13 \% \mathrm{w} / \mathrm{v})$ at $90{ }^{\circ} \mathrm{C}$ for $20 \mathrm{~min}$ and after cooling to $45{ }^{\circ} \mathrm{C}$, the milk was inoculated (1 unit $10 \mathrm{~L}-1)$ of each of Lactobacillus delbrueckii subsp. bulgaricus and Streptococcus thermophilus until the $\mathrm{pH}$ reached 4.5. The inoculated milk was separated into equivalent portions; one part was added free probiotic cells (approximately 1010 cfu g-1), whereas the other part was added beads (1 g beads per $10 \mathrm{~g}$ yogurt, $1 \mathrm{~g}$ beads containing $\sim 1010$ cfu g-1). Finally, all yogurt portions were stored at $4{ }^{\circ} \mathrm{C}$ for 42 days.

\subsection{Survey of the viability of free and microencapsulated probiotic bacteria into yogurt}

Analysis of bacterial enumeration was concluded through plate count on MRSGlucose-vancomycin-agar (MRS agar; QUELAB, Canada, Glucose; Merk, Germany and Vancomycin; Sigma, USA) for L. rhamnosus and MRS-Salicin-agar (MRS agar; QUELAB, Canada and Salicin; Sigma, USA) for L. acidophilus straight following the production of probiotic yogurt at time at 0 and during the 42 days period with one week interval time (the storage temperature was $5^{\circ} \mathrm{C}$ ) (Ansari \& Pourjafar, 2019b; Homayouni et al., 2018; H Pourjafar, Mirzaei, Ghasemnezhad, \& Homayouni rad, 2012; H Pourjafar, Noori, Gandomi, \& Akhondzadeh Basti, 2016; Shah, 2000).

Samples of two type yogurts (10 g of yogurt contains free cells and $10 \mathrm{~g}$ of yogurt contains beads) were diluted into $90 \mathrm{~mL}$ peptone water (0.1 g $100 \mathrm{~mL}-1)$ and $1 \mathrm{~mL}$ aliquot dilutions were introduced to all plates of the MRSGlucose-vancomycin-agar and MRS-Salicin- agar. For a production of the MRS-Glucosevancomycin-agar, Glucose $(10 \mathrm{~mL}$ solution at $10 \% \mathrm{w} / \mathrm{v})$ and vancomycin $(50 \mu \mathrm{g} \mathrm{mL}-1)$ were added to $90 \mathrm{~mL}$ of pure MRS agar. For a production of the MRS-Salicin-agar, Salicin (10 $\mathrm{mL}$ solution at $10 \% \mathrm{w} / \mathrm{v}$ ) was added to $90 \mathrm{~mL}$ of pure MRS agar. Finally, each medium was sterilized at $121.1{ }^{\circ} \mathrm{C}$ for $15 \mathrm{~min}$. The entire plates of L. rhamnosus and L. acidophilus were incubated at $37 \pm 2{ }^{\circ} \mathrm{C}$ for $48 \mathrm{~h}$ in the aerobic situation. The standards were expressed as colony-forming units per gram of sample (cfu g1) (Pourjafar et al., 2016; Saxelin et al., 2010; Shah, 2000).

To enumerate the microencapsulated probiotic bacteria within yogurt, the arrested probiotics were released from the beads. Ten grams of yogurt were blended with $90 \mathrm{~mL}$ of phosphate buffer ( $0.1 \mathrm{~mol} \mathrm{L-1,} \mathrm{pH} 7.0)$ followed by 60 min shaking in a bag blender (netechlaboratory, Bag Tech $\AA$ ). The yogurt sample counting free probiotic bacteria were treated in a similar fashion so to remain the same analogous action order. (See Fig. 2)

\subsection{Survey of the viability of free and microencapsulated probiotic bacteria under simulated gastrointestinal circumstances}

The survival rate of probiotic bacteria in simulated GI fluid was studied in 14, 28 and 42 days following inoculation of bacteria (in two types; free and encapsulated with double coating) in yogurt. In each study period $(14,28$, and 42 ) the samples ( $10 \mathrm{~g}$ of yogurt contains free cells and $10 \mathrm{~g}$ of yogurt contains beads) were placed separately in a tube counted by $100 \mathrm{~mL}$ of sterilized simulated gastric juice $(0.08 \mathrm{~mol} \mathrm{~L}$ $1 \mathrm{HCl}$, including $2 \mathrm{~g} \mathrm{~L}-1 \mathrm{NaCl}$, with $3 \mathrm{~g} \mathrm{~L}-1$ pepsin, $\mathrm{pH} 1.5$ ) and incubated for $30,60,90$, and $120 \mathrm{~min}$ at $37 \pm 2{ }^{\circ} \mathrm{C}$. Following the incubation, aliquots of $10 \mathrm{~g}$ of beads or $10 \mathrm{~mL}$ of free cell suspensions from the previous stage were transferred to $100 \mathrm{~mL}$ of sterilized simulated intestinal liquid (0.05 mol L-1 KH2PO4, with 10 $\mathrm{g}$ L-1 bile salt, $\mathrm{pH}$ 7.5). Subsequently, these tubes were incubated for $150 \mathrm{~min}$ at $37 \pm 2{ }^{\circ} \mathrm{C}$. Then samples were diluted with sterilized peptone water and $1 \mathrm{~mL}$ aliquot dilutions were 
dispensed in every plate of the MRS-Salicinagar and MRS-Glucose-vancomycin-agar. All counting plates of $L$. rhamnosus and $L$. acidophilus were incubated at $37 \pm 2{ }^{\circ} \mathrm{C}$ for $48 \mathrm{~h}$ in aerobic condition. To enumerate the microencapsulated bacteria, the arrested cells were released from the beads. The beads re-
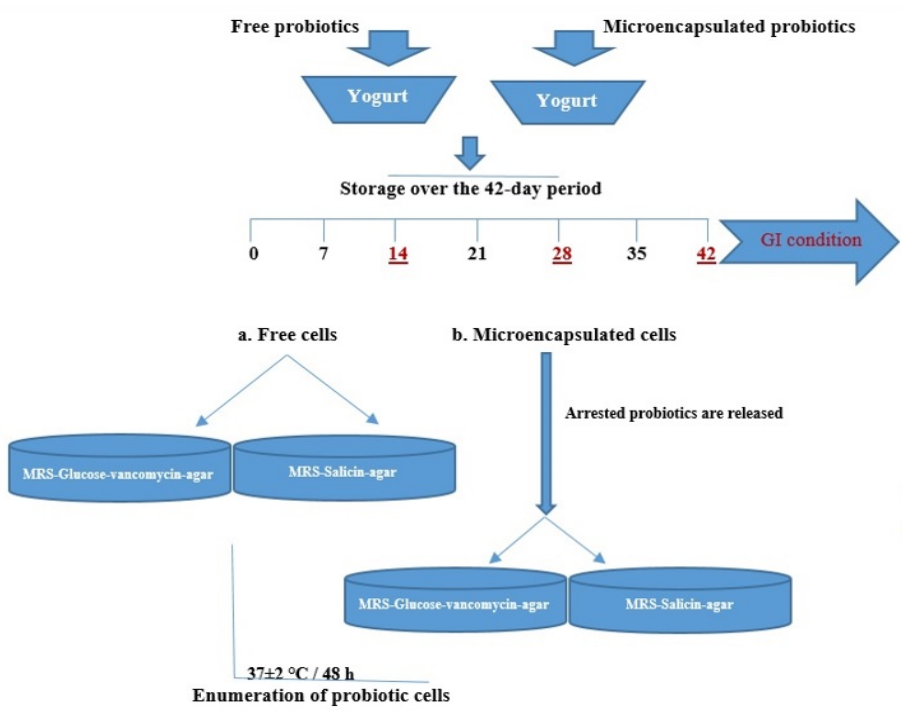

suspended in $90 \mathrm{~mL}$ of phosphate buffer $(0.1$ mol L-1, pH 7.0) followed by 60 min shaking in a bag blender (netech-laboratory, Bag Tech $\AA$ ) (Ansari \& Pourjafar, 2019a; Mirzaei et al., 2011; H Pourjafar et al., 2012; H Pourjafar et al., 2016; Shima, Morita, Yamashita, \& Adachi, 2006; Sultana et al., 2000). (See Fig. 2)

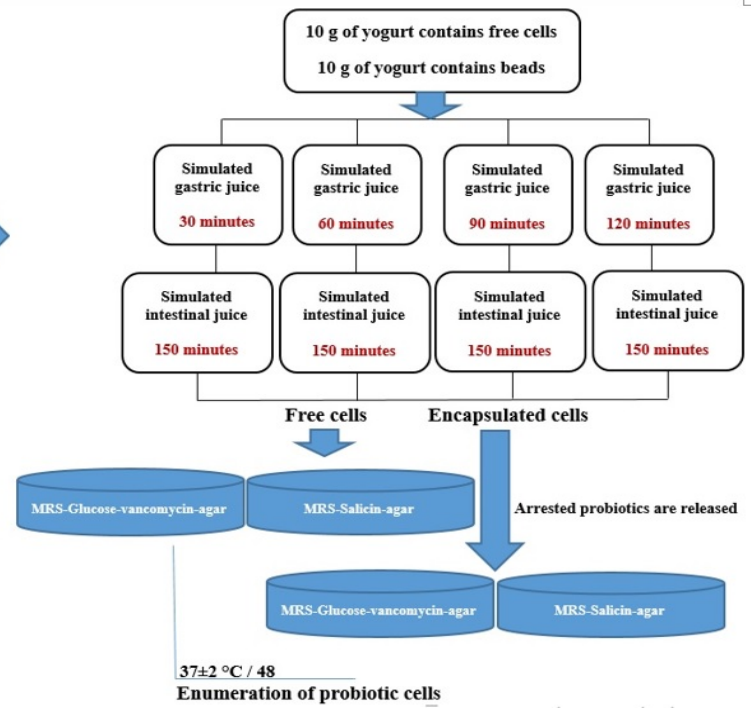

Figure 2. Survey of the viability of free and microencapsulated probiotic bacteria into yogurt following the production of probiotic yogurt at time at 0 and during the 42 days period with one week interval time (the storage temperature was $5^{\circ} \mathrm{C}$ ) (Left), and survey of the viability of free and microencapsulated probiotic bacteria under simulated gastrointestinal circumstances in 14, 28 and 42 days following inoculation of bacteria (in two types; free and encapsulated with double coating) in yogurt (Right)

\subsection{Assessment of acidity, pH, and} organoleptic characteristics

Acidity and $\mathrm{pH}$ of each product were determined in periods of $0,7,21$ and 42 days (at the same time of examination the survival rate of free and encapsulated bacteria). For acidity and $\mathrm{pH}$ measurement, Dornic method and $\mathrm{pH}$ meter (AZ-8601, Taiwan) were employed respectively. The assessments of the organoleptic characteristics of each product were done via 32 experts (taste panel) in the same condition as locality, lightness, and containers in periods of 7,21 and 42 days.

\subsection{Statistical analyses}

The viability of bacteria in samples of yogurt was assessed in 42 days storage period using Repeated Measures ANOVA test. The viability of bacteria in the GI simulation environment evaluated in periods of 14, 28 and 42 days after inoculation of bacteria by Repeated Measures ANOVA test. Friedman none-parametric test carried out for comparison of the mean of acidity, $\mathrm{pH}$, and organoleptic scores in different days and the mean values of yogurt containing free or coated probiotics and control group on each day were compared using Kruskal-Wallis test. The total assessments were obtained in triplicate.

\section{Results and discussions}

\subsection{Manufacture of Eudragit $\mathbf{S 1 0 0}$ nanoparticles and characteristics of beads}

In this study, 100-150 $\mathrm{nm}$ sized encapsulated particles were prepared through the homogenization of $\mathrm{Eu} \mathrm{S100}$ powder (26000 rpm, $10 \mathrm{~min}$ ). Hu et al. (Hu et al., 2012) also used Eu S100 powder and acetone solvent through the SAS technique to create nanoparticles of Eu S100. They attained regular 
and uniform nanoparticles with satisfactory size $(147 \mathrm{~nm})$. This study was performed at $35^{\circ} \mathrm{C}$ and at $15 \mathrm{MPa}$ pressure. In our investigation, we utilized the homogenization process to break particles instead of rising environmental pressure. In this way, the size of the obtained nanoparticles by our method was comparable to $\mathrm{Hu}$ et al. (Hu et al., 2012) examination. After preparation of the $\mathrm{Eu}$ S100 using SAS technique, the particle size and PDI of Eu S100 particles were $100 \mathrm{~nm}$ and 0.410 respectively. The ending diameter of the double coated beads was at about $80-200 \mu \mathrm{m}$.

3.2. The viability of free and microencapsulated probiotics in yogurt during storage time

Bacterial counts in yogurt containing free and microencapsulated probiotic bacteria are displayed in table 1. The bacterial count was taken twice for each sample and the mean of these repetitions is shown. The viability of bacteria decreased significantly during the study $(\mathrm{P}=0.027)$, and there were not any significant differences between microencapsulated and free-form bacteria in this case $(\mathrm{P}=0.360)$. Also, there was not any significant difference between the viability of two species of bacteria $(\mathrm{P}=0.408)$. In a similar study, Krasaekoopt et al. (2003, 2004) (Krasaekoopt, Bhandari, \& Deeth, $2003,2004)$ assessed the viability of $L$. acidophilus 574, L. casei 01 and B. bifidum 1994 microencapsulated in the only chitosan-coated alginate beads in yogurt product during storage time. The survival rate of the microencapsulated mentioned probiotics was higher than that of the free bacteria just about 1 log. The count of Lactobacilli was maintained higher than the 107 cfu g-1 (suggested therapeutic minimum) during storage, but not for the Bifidobacteria.

Calcium alginate makes a tender membrane between probiotics and harsh environmental circumstance; therefore we employed chitosan as an external layer to improve the strength of beads. Chitosan itself is vulnerable to deterioration via acids in low $\mathrm{pH}$ situations; therefore we coated a second layer of anionic $\mathrm{Eu}$ around cationic chitosan layer. This second layer is thin and improves the resistance of coated beads in the acidic state without major alteration in size of beads (Badhana et al., 2013; Chávarri et al., 2010; Kanmani et al., 2011; Liserre, Re, \& Franco, 2007).

\subsection{The viability of free and microencapsulated probiotics under simulated gastrointestinal conditions}

In this study, to determine the effect of the acidic juice of the stomach and the bile of the intestine on the viability of microencapsulated probiotic bacteria, an in vitro method was employed. Bacterial count in simulated GI conditions is displayed in table 2 . The viability of bacteria decreased significantly during the study period $(\mathrm{P}<0.01)$ and during the measurement time $(\mathrm{P}<0.01)$. Lactobacillus acidophilus was more stable in comparison with Lactobacillus rhamnosus $\quad(\mathrm{P}<0.01)$ and mirocoated bacteria were more stable than free bacteria $(\mathrm{P}<0.01)$.

There are several studies on the viability of the free and encapsulated of probiotic microorganisms under the simulated GI conditions (Chávarri et al., 2010; Hansen, AllanWojtas, Jin, \& Paulson, 2002; Kanmani et al., 2011; Krasaekoopt \& Watcharapoka, 2014; Mirzaei et al., 2011). In our investigation, we had an efficient new and modified approach to producing beads. We employed a second layer of nanoparticle Eu S100 which could enhance probiotic bacteria ( $L$. acidophilus and $L$. rhamnosus) survival rate through storage time as well as simulated GI situation. We assessed the survival rate of mentioned probiotics under simulated GI circumstance in elected days throughout the storage time which has not been considered in previous studies. In these studies, beads were moved to simulate GI situation accurately the following production. Nevertheless, in our investigation, we primarily inserted beads into the yogurt and monitored the survival rate of probiotic microorganisms into the product itself. We also gathered beads from the yogurt in elected days and studied the viability of probiotics in simulated GI situations at the equivalent time. 
Table 1. Bacterial viability (Mean \pm SD) comparison of yogurt in lab environment

\begin{tabular}{|l|l|l|l|l|l|l|l|l|}
\hline $\begin{array}{l}\text { Experimental } \\
\text { Group }\end{array}$ & Bacteria & Day 0 & Day 7 & Day 14 & Day 21 & Day 28 & Day 35 \\
\hline \multirow{2}{*}{ Free } & $\begin{array}{l}\text { Lactobacillus } \\
\text { acidophilus }\end{array}$ & $7.0 \times 10^{8} \pm 9.9 \times 10^{7}$ & $2.3 \times 10^{8} \pm 2.1 \times 10^{6}$ & $1.9 \times 10^{8} \pm 1.8 \times 10^{7}$ & $4.2 \times 10^{7} \pm 9.9 \times 10^{6}$ & $1.8 \times 10^{7} \pm 1.1 \times 10^{7}$ & $6.9 \times 10^{6} \pm 3.4 \times 10^{6}$ & $4.2 \times 10^{6} \pm 2.2 \times 10^{6}$ \\
\cline { 2 - 8 } & $\begin{array}{l}\text { Lactobacillus } \\
\text { rhamnosus }\end{array}$ & $3.2 \times 10^{9} \pm 2.8 \times 10^{8}$ & $2.7 \times 10^{8} \pm 1.0 \times 10^{8}$ & $1.9 \times 10^{8} \pm 5.5 \times 10^{7}$ & $5.1 \times 10^{7} \pm 5.1 \times 10^{7}$ & $2.7 \times 10^{7} \pm 1.1 \times 10^{6}$ & $1.3 \times 10^{6} \pm 1.6 \times 10^{6}$ & $5.8 \times 10^{6} \pm 6.3 \times 10^{6}$ \\
\hline \multirow{2}{*}{ Encapsulated } & $\begin{array}{l}\text { Lactobacillus } \\
\text { acidophilus }\end{array}$ & $3.3 \times 10^{7} \pm 1.1 \times 10^{7}$ & $5.2 \times 10^{7} \pm 1.6 \times 10^{7}$ & $4.1 \times 10^{7} \pm 2.0 \times 10^{7}$ & $1.9 \times 10^{7} \pm 1.3 \times 10^{7}$ & $1.5 \times 10^{7} \pm 8.4 \times 10^{5}$ & $2.7 \times 10^{7} \pm 1.3 \times 10^{6}$ & $2.5 \times 10^{7} \pm 1.1 \times 10^{6}$ \\
\cline { 2 - 8 } & $\begin{array}{l}\text { Lactobacillus } \\
\text { rhamnosus }\end{array}$ & $7.6 \times 10^{9} \pm 4.2 \times 10^{9}$ & $2.0 \times 10^{9} \pm 2.5 \times 10^{8}$ & $2.2 \times 10^{9} \pm 4.9 \times 10^{7}$ & $2.4 \times 10^{9} \pm 4.7 \times 10^{8}$ & $1.5 \times 10^{9} \pm 3.7 \times 10^{8}$ & $3.2 \times 10^{8} \pm 9.9 \times 10^{7}$ & $3.4 \times 10^{8} \pm 9.9 \times 10^{7}$ \\
\hline
\end{tabular}

Table 2. Bacterial viability (Mean \pm SD) comparison of yogurt in the simulated gastrointestinal conditions

\begin{tabular}{|c|c|c|c|c|c|c|c|}
\hline Day & $\begin{array}{l}\text { Experimental } \\
\text { Group }\end{array}$ & Bacteria & 0 min & $30 \mathrm{~min}$ & $60 \mathrm{~min}$ & $90 \mathrm{~min}$ & $120 \min$ \\
\hline \multirow{4}{*}{14} & \multirow[b]{2}{*}{ Free } & Lactobacillus acidophilus & $2.0 \times 10^{8} \pm 0.0 \times 10^{1}$ & $1.0 \times 10^{7} \pm 7.1 \times 10^{5}$ & $7.4 \times 10^{6} \pm 1.4 \times 10^{5}$ & $3.1 \times 10^{4} \pm 7.1 \times 10^{2}$ & $1.3 \times 10^{3} \pm 1.4 \times 10^{2}$ \\
\hline & & Lactobacillus rhamnosus & $1.3 \times 10^{8} \pm 2.1 \times 10^{7}$ & $8.8 \times 10^{6} \pm 4.2 \times 10^{5}$ & $3.2 \times 10^{5} \pm 0.0 \times 10^{1}$ & $2.8 \times 10^{4} \pm 7.1 \times 10^{2}$ & $1.2 \times 10^{3} \pm 1.4 \times 10^{2}$ \\
\hline & \multirow{2}{*}{ Microencapsulated } & Lactobacillus acidophilus & $5.0 \times 10^{7} \pm 7.8 \times 10^{6}$ & $4.3 \times 10^{7} \pm 2.8 \times 10^{6}$ & $7.6 \times 10^{6} \pm 7.1 \times 10^{4}$ & $6.8 \times 10^{6} \pm 4.2 \times 10^{5}$ & $5.6 \times 10^{5} \pm 3.5 \times 10^{4}$ \\
\hline & & Lactobacillus rhamnosus & $2.6 \times 10^{9} \pm 7.8 \times 10^{8}$ & $1.0 \times 10^{9} \pm 0.0 \times 10^{1}$ & $7.3 \times 10^{8} \pm 2.4 \times 10^{8}$ & $1.7 \times 10^{8} \pm 1.4 \times 10^{7}$ & $2.5 \times 10^{7} \pm 1.5 \times 10^{7}$ \\
\hline \multirow{4}{*}{28} & \multirow{2}{*}{ Free } & Lactobacillus acidophilus & $1.5 \times 10^{7} \pm 0.0 \times 10^{1}$ & $2.4 \times 10^{5} \pm 7.1 \times 10^{3}$ & $8.6 \times 10^{4} \pm 1.4 \times 10^{3}$ & $3.3 \times 10^{3} \pm 2.8 \times 10^{2}$ & $2.9 \times 10^{2} \pm 7.0 \times 10^{1}$ \\
\hline & & Lactobacillus rhamnosus & $2.5 \times 10^{7} \pm 0.0 \times 10^{1}$ & $9.3 \times 10^{5} \pm 2.8 \times 10^{4}$ & $3.5 \times 10^{4} \pm 2.8 \times 10^{3}$ & $2.7 \times 10^{3} \pm 2.8 \times 10^{2}$ & $1.3 \times 10^{2} \pm 2.8 \times 10^{1}$ \\
\hline & \multirow{2}{*}{ Microencapsulated } & Lactobacillus acidophilus & $1.6 \times 10^{7} \pm 1.4 \times 10^{6}$ & $1.3 \times 10^{7} \pm 2.8 \times 10^{6}$ & $8.2 \times 10^{6} \pm 2.1 \times 10^{5}$ & $2.6 \times 10^{6} \pm 8.5 \times 10^{5}$ & $6.8 \times 10^{5} \pm 4.9 \times 10^{4}$ \\
\hline & & Lactobacillus rhamnosus & $1.5 \times 10^{9} \pm 7.1 \times 10^{7}$ & $1.0 \times 10^{9} \pm 7.1 \times 10^{7}$ & $7.3 \times 10^{8} \pm 2.1 \times 10^{7}$ & $9.5 \times 10^{6} \pm 7.1 \times 10^{5}$ & $1.2 \times 10^{5} \pm 7.1 \times 10^{3}$ \\
\hline \multirow{4}{*}{42} & \multirow{2}{*}{ Free } & Lactobacillus acidophilus & $2.7 \times 10^{6} \pm 1.4 \times 10^{5}$ & $2.7 \times 10^{4} \pm 6.4 \times 10^{3}$ & $3.9 \times 10^{2} \pm 1.2 \times 10^{2}$ & $1.9 \times 10^{1} \pm 1.4 \times 10^{0}$ & $2.0 \times 10^{0} \pm 1.4 \times 10^{0}$ \\
\hline & & Lactobacillus rhamnosus & $1.1 \times 10^{6} \pm 7.1 \times 10^{4}$ & $6.0 \times 10^{3} \pm 6.4 \times 10^{2}$ & $2.1 \times 10^{2} \pm 4.9 \times 10^{1}$ & $4.0 \times 10^{1} \pm 2.1 \times 10^{1}$ & $5.0 \times 10^{0} \pm 4.2 \times 10^{0}$ \\
\hline & \multirow[t]{2}{*}{ Microencapsulated } & Lactobacillus acidophilus & $1.5 \times 10^{7} \pm 4.9 \times 10^{6}$ & $1.6 \times 10^{6} \pm 1.4 \times 10^{5}$ & $5.1 \times 10^{6} \pm 5.8 \times 10^{6}$ & $4.3 \times 10^{5} \pm 1.2 \times 10^{5}$ & $2.8 \times 10^{4} \pm 1.8 \times 10^{4}$ \\
\hline & & Lactobacillus rhamnosus & $3.1 \times 10^{8} \pm 1.4 \times 10^{7}$ & $6.0 \times 10^{7} \pm 4.4 \times 10^{7}$ & $4.5 \times 10^{6} \pm 1.6 \times 10^{6}$ & $3.4 \times 10^{5} \pm 1.3 \times 10^{5}$ & $2.8 \times 10^{4} \pm 4.9 \times 10^{3}$ \\
\hline
\end{tabular}




\subsection{Acidity and pH of yogurt samples during} 42 days storage

Acidity and $\mathrm{pH}$ of yogurt samples were evaluated on days $0,7,21$ and 42 following incubation and results are shown in Table 3. Throughout the storage period the acidity and $\mathrm{pH}$ were diminished and increased respectively in all samples. In yogurt samples containing the free-form of bacteria acidity and $\mathrm{pH}$, alterations were more dramatic than those of encapsulated and control groups. After the day 21, the differences between $\mathrm{pH}$ and acidity of yogurt containing the free and microencapsulated form of probiotics were considerable and the latter remained its $\mathrm{pH}$ and acidity at a value close to the control group.

\subsection{Organoleptic assessments}

Organoleptic scores of yogurt containing the free form of bacteria were the best on the first day but reduced substantially during 42 days of storage. Yogurt containing microencapsulated probiotics, however, maintained its acceptability during the experiment. The flavor of this group was significantly better than yogurt containing the free form of bacteria at day 42, so the maintenance of the flavor was the main organoleptic characteristic improved by microencapsulation (See Table 4).

Table 3. Acidity and $\mathrm{pH}$ of $0,7,21$ and 42 days old yogurt (Mean $\pm \mathrm{SD}$ ) in different experimental groups

\begin{tabular}{|c|l|l|l|}
\hline Time of measuring (day) & Group & $\mathbf{p H}$ & Acidity $\left({ }^{\circ} \mathbf{D}\right)$ \\
\hline \multirow{4}{*}{$\mathbf{0}$} & Free Bacteria & $4.49 \pm 0.10^{\mathrm{ABDa}}$ & $90.75 \pm 1.06^{\mathrm{ABa}}$ \\
\cline { 2 - 4 } & $\begin{array}{l}\text { Microencapsulated } \\
\text { bacteria }\end{array}$ & $4.49 \pm 0.00^{\mathrm{Aa}}$ & $90.50 \pm 0.70^{\mathrm{Aa}}$ \\
\cline { 2 - 4 } & Control & $4.50 \pm 0.00^{\mathrm{Aa}}$ & $89.95 \pm 1.34^{\mathrm{Aa}}$ \\
\hline \multirow{3}{*}{7} & Free Bacteria & $4.41 \pm 0.00^{\mathrm{BCa}}$ & $95.50 \pm 0.42^{\mathrm{Ba}}$ \\
\cline { 2 - 4 } & $\begin{array}{l}\text { Microencapsulated } \\
\text { bacteria }\end{array}$ & $4.44 \pm 0.05^{\mathrm{Aa}}$ & $94.25 \pm 0.35^{\mathrm{Aa}}$ \\
\cline { 2 - 4 } & Control & $4.45 \pm 0.00^{\mathrm{Aa}}$ & $93.60 \pm 0.56^{\mathrm{Aa}}$ \\
\hline \multirow{3}{*}{21} & Free Bacteria & $3.82 \pm 0.00^{\mathrm{Cb}}$ & $116.90 \pm 0.14^{\mathrm{Ab}}$ \\
\cline { 2 - 4 } & $\begin{array}{l}\text { Microencapsulated } \\
\text { bacteria }\end{array}$ & $4.14 \pm 0.00^{\mathrm{Aa}}$ & $99.00 \pm 0.00^{\mathrm{Aa}}$ \\
\cline { 2 - 4 } & Control & $4.16 \pm 0.02^{\mathrm{Aa}}$ & $98.50 \pm 0.00^{\mathrm{Ac}}$ \\
\hline \multirow{4}{*}{42} & Free Bacteria & $3.66 \pm 0.01^{\mathrm{DCa}}$ & $152.00 \pm 0.00^{\mathrm{Db}}$ \\
\cline { 2 - 4 } & $\begin{array}{l}\text { Microencapsulated } \\
\text { bacteria }\end{array}$ & $4.07 \pm 0.02^{\mathrm{Aa}}$ & $103.75 \pm 0.35^{\mathrm{Aa}}$ \\
\cline { 2 - 4 } & Control & $4.05 \pm 0.56^{\mathrm{Aa}}$ & $101.40 \pm 0.56^{\mathrm{Ac}}$ \\
\hline
\end{tabular}

Different lowercase letters indicate significant differences between groups in each day, and different uppercases indicate significant differences in each group between days.

Table 4. Organoleptic scores of 7, 21 and 42 day old yogurt (Mean \pm SD) in different experimental groups

\begin{tabular}{|l|l|l|l|l|l|}
\hline $\begin{array}{l}\text { Time of } \\
\text { measuring } \\
\text { (day) }\end{array}$ & Group & Color (from 5) & $\begin{array}{l}\text { Texture } \\
\text { (from 5) }\end{array}$ & $\begin{array}{l}\text { Flavor } \\
\text { (from 10) }\end{array}$ & $\begin{array}{l}\text { Total } \\
\text { (from 20) }\end{array}$ \\
\hline 7 & Free Bacteria & $4.75 \pm 0.44^{\mathrm{Aa}}$ & $4.63 \pm 0.49^{\mathrm{Aa}}$ & $9.22 \pm 1.2^{\mathrm{Aa}}$ & $18.59 \pm 1.68^{\mathrm{Aa}}$ \\
\cline { 2 - 5 } & $\begin{array}{l}\text { Microencapsulated } \\
\text { bacteria }\end{array}$ & $4.53 \pm 0.67^{\mathrm{Aa}}$ & $3.13 \pm 0.98^{\mathrm{Ab}}$ & $\begin{array}{l}8.84 \\
1.35^{\mathrm{Aa}}\end{array}$ & $16.47 \pm 2.30^{\mathrm{Ab}}$ \\
\hline
\end{tabular}




\begin{tabular}{|l|l|l|l|ll|l|}
\hline & Control & $4.59 \pm 0.50^{\mathrm{Aa}}$ & $4.50 \pm 0.57^{\mathrm{Aa}}$ & $\begin{array}{l}8.97 \\
1.23^{\mathrm{Aa}}\end{array}$ & \pm & $18.06 \pm 1.64^{\mathrm{Aa}}$ \\
\hline \multirow{4}{*}{21} & Free Bacteria & $4.81 \pm 0.40^{\mathrm{Aa}}$ & $4.69 \pm 0.47^{\mathrm{Aa}}$ & $\begin{array}{l}9.28 \\
0.96^{\mathrm{Aa}}\end{array}$ & \pm & $18.75 \pm 1.59^{\mathrm{Aa}}$ \\
\cline { 2 - 7 } & $\begin{array}{l}\text { Microencapsulated } \\
\text { bacteria }\end{array}$ & $4.66 \pm 0.54^{\mathrm{Aa}}$ & $3.06 \pm 1.01^{\mathrm{Ab}}$ & $\begin{array}{l}8.69 \\
1.31^{\mathrm{Aa}}\end{array}$ & \pm & $16.44 \pm 2.09^{\mathrm{Ab}}$ \\
\cline { 2 - 7 } & Control & $4.72 \pm 0.46^{\mathrm{Aa}}$ & $4.47 \pm 0.62^{\mathrm{Aa}}$ & $\begin{array}{l}8.88 \\
1.18^{\mathrm{Aa}}\end{array}$ & \pm & $18.06 \pm 1.72^{\mathrm{Aa}}$ \\
\hline \multirow{4}{*}{} & Free Bacteria & $4.34 \pm 0.54^{\mathrm{Ba}}$ & $4.00 \pm 0.76^{\mathrm{Ba}}$ & $\begin{array}{l}7.88 \pm 1.13 \\
\mathrm{Ba}\end{array}$ & $16.19 \pm 1.71^{\mathrm{Ba}}$ \\
\cline { 2 - 7 } & $\begin{array}{l}\text { Microencapsulated } \\
\text { bacteria }\end{array}$ & $4.47 \pm 0.51^{\mathrm{Aa}}$ & $3.03 \pm 1.06^{\mathrm{Ab}}$ & $\begin{array}{l}8.67 \\
1.00^{\mathrm{Ab}}\end{array}$ & \pm & $16.13 \pm 1.91^{\mathrm{Aa}}$ \\
\cline { 2 - 6 } & Control & $4.38 \pm 0.71^{\mathrm{Aa}}$ & $4.31 \pm 0.69^{\mathrm{Aa}}$ & $\begin{array}{l}8.09 \pm \\
1.61^{\mathrm{Aab}}\end{array}$ & $16.78 \pm 2.21^{\mathrm{Aa}}$ \\
\hline
\end{tabular}

Different lower-case letters indicate significant differences between groups in each day and capital case letters indicate significant differences between days of measurement for each item in each group.

\section{Conclusions}

In this study, we presented a method of microencapsulation to produce an efficient probiotic yogurt. L. rhamnosus and $L$. acidophilus were microencapsulated with calcium alginate, and then double layer coating of these beads with chitosan and $\mathrm{Eu} \mathrm{S100}$ nanoparticles carried out. The results of this study suggest that this technique of microencapsulation can improve the viability of L. rhamnosus and L. acidophilus in yogurt and in the simulated human GI tract. This method can also reduce the metabolic activity of the contained bacteria; consequently, $\mathrm{pH}$ and acidity of the final product stayed at an acceptable level during storage time. The consistency of $\mathrm{pH}$ and acidity of the product had considerable effects on maintaining taste and flavor during this period, and may also improve the viability of bacteria by decreasing bacterial cell damages. The second coating layer (Eu S100nanoparticles) adds resistance to the beads and can help them to reach their target functional place (Colon). The final product had appropriate acceptability; however, its texture was not competitive with other experimental groups, so there is a need to do more researches to improve the acceptability of final products. It is also necessary to investigate the application of this method of microencapsulation in other dairy products such as cheese, ice cream, fruit yogurt, and kefir as well as under in vivo GI conditions.

\section{References}

Abdolhosseinzadeh, E., Dehnad, A. R., Pourjafar, H., Homayouni, A., \& Ansari, F. (2018). The production of probiotic Scallion Yogurt: Viability of Lactobacillus acidophilus freely and microencapsulated in the product. Carpathian Journal of Food Science \& Technology, 10(3), 72-80.

Abouhussein, D. M., El-bary, A. A., Shalaby, S. H., \& El Nabarawi, M. A. (2016). Chitosan mucoadhesive buccal films: effect of different casting solvents on their physicochemical properties. International Journal of Pharmacy and Pharmaceutical Sciences, 8(9), 206-213 .

Ahmed, T. A., \& Aljaeid, B. M. (2016). Preparation, characterization, and potential application of chitosan, chitosan derivatives, and chitosan metal nanoparticles in pharmaceutical drug delivery. Drug design, development and therapy, 10, 483 .

Akın, M., Akın, M., \& Kırmacı, Z. (2007). Effects of inulin and sugar levels on the viability of yogurt and probiotic bacteria and 
the physical and sensory characteristics in probiotic ice-cream. Food Chemistry, 104(1), 93-99 .

Anal, A. K., \& Singh, H. (2007). Recent advances in microencapsulation of probiotics for industrial applications and targeted delivery. Trends in Food Science \& Technology, 18(5), 240-251 .

Ansari, F., \& Pourjafar, H. (2019a). Comment on Traditional fermented fish harbors bacteria with potent probiotic and anticancer properties. Biocatalysis and Agricultural Biotechnology, 17, 269-270 .

Ansari, F., \& Pourjafar, H. (2019b). Comments on Evaluation of Chios mastic gum as antimicrobial agent and matrix forming material targeting probiotic cell encapsulation for functional fermented milk production. LWT-Food Science and Technology, 109, 366 .

Ansari, F., Pourjafar, H., Jodat, V., Sahebi, J., \& Ataei, A. (2017). Effect of Eudragit S100 nanoparticles and alginate chitosan encapsulation on the viability of Lactobacillus acidophilus and Lactobacillus rhamnosus. AMB Express, 7(1), 144.

Ansari, F., Pourjafar, H., Tabrizi, A., Homayouni, A. (2020). The effects of probiotics and prebiotics on mental disorders: A review on depression, anxiety, alzheimer, and autism spectrum disorders. Current Pharmaceutical Biotechnology, 21(7), 555-565.

Badhana, S., Garud, N., \& Garud, A. (2013). Colon specific drug delivery of mesalamine using eudragit S100-coated chitosan microspheres for the treatment of ulcerative colitis. International Current Pharmaceutical Journal, 2(3), 42-48 .

Bernet, M.-F., Brassart, D., Neeser, J., \& Servin, A. (1994). Lactobacillus acidophilus LA 1 binds to cultured human intestinal cell lines and inhibits cell attachment and cell invasion by enterovirulent bacteria. Gut, 35(4), 483489 .

Chávarri, M., Marañón, I., Ares, R., Ibáñez, F. C., Marzo, F., \& del Carmen Villarán, M. (2010). Microencapsulation of a probiotic and prebiotic in alginate-chitosan capsules improves survival in simulated gastrointestinal conditions. International Journal of Food Microbiology, 142(1), 185-189 .

Crcarevska, M. S., Dodov, M. G., \& Goracinova, K. (2008). Chitosan coated Caalginate microparticles loaded with budesonide for delivery to the inflamed colonic mucosa. European Journal of Pharmaceutics and Biopharmaceutics, 68(3), 565-578 .

Frederico, C., Pinto, T. B., Castro, E. M., Suguimoto, H. H., De Santana, E. H. W., Alegro, L. C. A., \& De Souza, C. H. B. (2016). Probiotic dairy dessert supplemented with whey protein concentrate: effect on the viability of Lactobacillus acidophilus, on texture, physicochemical and sensory features. Journal of Food and Nutrition Research, 55(1), 48-56.

Ghasemnezhad, R., Razavilar, V., Pourjafar, H., Khosravi-Darani, K., \& Ala, K. (2017). The Viability of Free and Encapsulated Lactobacillus casei and Bifidobacterium animalis in Chocolate Milk, and Evaluation of Its pH Changes and Sensory Properties during Storage. Annual Research and Review in Biology, 21(3), 1-8.

Gibson, G. R., Probert, H. M., Van Loo, J., Rastall, R. A., \& Roberfroid, M. B. (2004). Dietary modulation of the human colonic microbiota: updating the concept of prebiotics. Nutrition Research Reviews, 17(02), 259-275 . 
Granato, D., Branco, G. F., Cruz, A. G., Faria, J. d. A. F., \& Shah, N. P. (2010). Probiotic dairy products as functional foods. Comprehensive Reviews in Food Science and Food Safety, 9(5), 455-470 .

Hansen, L. T., Allan-Wojtas, P., Jin, Y.-L., \& Paulson, A. (2002). Survival of Ca-alginate microencapsulated Bifidobacterium spp. in milk and simulated gastrointestinal conditions. Food Microbiology, 19(1), 3545 .

Hari, B. V., Lu, C.-L., Narayanan, N., Wang, R.R., \& Zheng, Y.-T. (2016). Engineered polymeric nanoparticles of Efavirenz: Dissolution enhancement through particle size reduction. Chemical Engineering Science, 155, 366-375 .

Hekmat, S., \& Reid, G. (2006). Sensory properties of probiotic yogurt is comparable to standard yogurt. Nutrition Research, 26(4), 163-166 .

Homayouni, A., Javadi, M., Ansari, F., Pourjafar, H., Jafarzadeh, M., \& Barzegar, A. (2018). Advanced methods in ice cream analysis: A review. Food Analytical Methods, 11(11), 3224-3234.

Hu, D., Liu, L., Chen, W., Li, S., \& Zhao, Y. (2012). A novel preparation method for 5aminosalicylic acid loaded Eudragit S100 nanoparticles. International Journal of Molecular Sciences, 13(5), 6454-6468 .

Huang, C.-H., Shen, C.-C., Liang, Y.-C., \& Jan, T.-R. (2016). The probiotic activity of Lactobacillus murinus against food allergy. Journal of Functional Foods, 25, 231-241 .

Kandasamy, S., Vlasova, A.N., Fischer, D., Kumar, A., Chattha, K.S., Rauf, A., Shao, L., Langel, S.N., Rajashekara, G. and Saif, L.J. (2016). Differential Effects of Escherichia coli Nissle and Lactobacillus rhamnosus Strain GG on Human Rotavirus Binding,
Infection, and B Cell Immunity. The Journal of Immunology, 196(4), 1780-1789 .

Kanmani, P., Kumar, R. S., Yuvaraj, N., Paari, K., Pattukumar, V., \& Arul, V. (2011). Cryopreservation and microencapsulation of a probiotic in alginate-chitosan capsules improves survival in simulated gastrointestinal conditions. Biotechnology and Bioprocess Engineering, 16(6), 11061114 .

Krasaekoopt, W., Bhandari, B., \& Deeth, H. (2003). Evaluation of encapsulation techniques of probiotics for yoghurt. International Dairy Journal, 13(1), 3-13 .

Krasaekoopt, W., Bhandari, B., \& Deeth, H. (2004). The influence of coating materials on some properties of alginate beads and survivability of microencapsulated probiotic bacteria. International Dairy Journal, 14(8), 737-743.

Krasaekoopt, W., \& Watcharapoka, S. (2014). Effect of addition of inulin and galactooligosaccharide on the survival of microencapsulated probiotics in alginate beads coated with chitosan in simulated digestive system, yogurt and fruit juice. LWT-Food Science and Technology, 57(2), 761-766

Lee, J., Cha, D., \& Park, H. J. (2004). Survival of freeze-dried Lactobacillus bulgaricus KFRI 673 in chitosan-coated calcium alginate microparticles. Journal of Agricultural and Food Chemistry, 52(24), 7300-7305.

Liserre, A. M., Re, M. I., \& Franco, B. D. (2007). Microencapsulation of Bifidobacterium animalis subsp. lactis in modified alginate-chitosan beads and evaluation of survival in simulated gastrointestinal conditions. Food Biotechnology, 21(1), 1-16 . 
Mirzaei, H., Pourjafar, H., \& Rad, A. H. (2011). The effect of microencapsulation with calcium alginate and resistant starch on the Lactobacillus acidophilus (La5) survival rate in simulated gastrointestinal juice conditions. Journal of Veterinary Research, 66(4), 337-377.

Mortazavian, A., Ehsani, M., Mousavi, S., Rezaei, K., Sohrabvandi, S., \& Reinheimer, J. (2007). Effect of refrigerated storage temperature on the viability of probiotic micro-organisms in yogurt. International Journal of Dairy Technology, 60(2), 123127 .

Pourjafar, H., Mirzaei, H., Ghasemnezhad, R., \& Homayouni, A. (2012). Study of morphological and protective characteristics of beads obtained from microencapsulation of Lactobacillus acidophilus probiotic as a predominant and natural flora in human gut. Annals of Military and Health Science Research, 9(4), 233-240 .

Pourjafar, H., Noori, N., Gandomi, H., \& Akhondzadeh Basti, A. (2016). Study of protective role of double coated beads of calcium alginate-chitosan-eudragit s100 nanoparticles achieved from microencapsulation of Lactobacillus acidophilus as a predominant flora of human and animals gut. Journal of Veterinary Research, 71(3), 311-320 .

Pourjafar, H., Noori, N., Gandomi, H., Basti, A. A., \& Ansari, F. (2018). Stability and efficiency of double-coated beads containing lactobacillus acidophilus obtained from the calcium alginate-chitosan and Eudragit S100 nanoparticles microencapsulation. International Journal of Probiotics \& Prebiotics, 13 (2/3), 77-84.

Ranadheera, C. S., Evans, C., Adams, M., \& Baines, S. (2012). Probiotic viability and physico-chemical and sensory properties of plain and stirred fruit yogurts made from goat's milk. Food Chemistry, 135(3), 14111418 .

Rijkers, G.T., Bengmark, S., Enck, P., Haller, D., Herz, U., Kalliomaki, M., Kudo, S., Lenoir-Wijnkoop, I., Mercenier, A., Myllyluoma, E. and Rabot, S. (2010). Guidance for substantiating the evidence for beneficial effects of probiotics: current status and recommendations for future research. The Journal of Nutrition, 140(3), 671S-676S .

Rocha, J. M. F. (2016). Microencapsulation of probiotic bacteria. EC Microbiology, 3(4), 480-481.

Saxelin, M., Lassig, A., Karjalainen, H., Tynkkynen, S., Surakka, A., Vapaatalo, H., Järvenpää, S., Korpela, R., Mutanen, M. and Hatakka, K. (2010). Persistence of probiotic strains in the gastrointestinal tract when administered as capsules, yoghurt, or cheese. International Journal of Food Microbiology, 144(2), 293-300 .

Shah, N. (2000). Probiotic bacteria: selective enumeration and survival in dairy foods. Journal of Dairy Science, 83(4), 894-907 .

Shima, M., Morita, Y., Yamashita, M., \& Adachi, S. (2006). Protection of Lactobacillus acidophilus from the low $\mathrm{pH}$ of a model gastric juice by incorporation in a W/O/W emulsion. Food Hydrocolloids, 20(8), 1164-1169.

Sultana, K., Godward, G., Reynolds, N., Arumugaswamy, R., Peiris, P., \& Kailasapathy, K. (2000). Encapsulation of probiotic bacteria with alginate-starch and evaluation of survival in simulated gastrointestinal conditions and in yoghurt. International Journal of Food Microbiology, 62(1), 47-55. 
Tabrizi, A., Khalili, L., Homayouni-Rad, A., Pourjafar, H., Dehghan, P., \& Ansari, F. (2019). Psychobiotics, as Promising Functional Food to Patients with Psychological Disorders: A Review on Mood Disorders, Sleep, and Cognition. NeuroQuantology, 17(6), 1-9.

Thakral, S., Thakral, N. K., \& Majumdar, D. K. (2013). Eudragit $\AA$ : a technology evaluation. Expert Opinion on Drug Delivery, 10(1), 131-149.

Yoo, J.-W., Giri, N., \& Lee, C. H. (2011). pHsensitive Eudragit nanoparticles for mucosal drug delivery. International Journal of Pharmaceutics, 403(1), 262-267.

Younis, N., Shaheen, M. A., \& Abdallah, M. H. (2016). Silymarin-loaded Eudragit ${ }^{\circledR}$ RS100 nanoparticles improved the ability of silymarin to resolve hepatic fibrosis in bile duct ligated rats. Biomedicine \& Pharmacotherapy, 81, 93-103 .

\section{Acknowledgment}

This article is related to a $\mathrm{PhD}$ thesis (No. 612- Hadi Pourjafar) from University of Tehran; its preparation and investigate work was supported by the Department of Food Hygiene, Tehran, Iran. 